\title{
Electrochemical modification of platinum and glassy carbon surfaces with pyridine layers and their use as complexing agents for copper (II) ions
}

https://doi.org/10.1515/chem-2019-0084

received December 15, 2018; accepted March 19, 2019.

\begin{abstract}
The electrochemical grafting of the "in-situ" prepared diazopyridinium salt have permitted the attachment of pyridine moieties onto platinum and glassy carbon surfaces. The modification of the electrode surfaces is observed by a redox probe. The ability of the film for the complexation of copper (II) ions is demonstrated by square wave voltammetry. After $45 \mathrm{~min}$ accumulation of copper (II) ions onto the grafted electrode surfaces, the electrode signal obtained by square wave voltammetry measurement served to discriminate the adsorbed heavy metal ions. Such measurements showed that the grafted pyridine has the ability to display complexing behavior toward some heavy metal ions. DFT calculations support a strong binding of the pyridine moieties onto the Pt surface. The most favorable complexation mode of copper (II) ions as suggested from DFT is the bidentate complex. This strategy is vital in constructing a wide range of different electrochemical sensors.
\end{abstract}

Keywords: Electrochemical grafting; Heterocyclic diazonium salts; Surface complexation; Square wave voltammetry.

\section{Introduction}

Electrochemical reduction of aryldiazonium salts, at quite low electrode potential, has permitted the modification of the electrode surface with aryl moieties [1] which may serve as physical barriers or platforms for further modifications

\footnotetext{
*Corresponding authosr: Avni Berisha, Fetah I. Podvorica, Department of Chemistry, FNMS, University of Pristina "Hasan Prishtina”, 10000 Pristina, Kosovo, E-mails: fetah.podvorica@uni-pr.edu; avni.berisha@uni-pr.edu

Veton Haziri, Department of Chemistry, FNMS, University of Pristina

"Hasan Prishtina", 10000 Pristina, Kosovo
}

[2-4] or are used in molecular electronics and bio sensing $[5,6]$. Aryl radicals that are created immediately after the reduction of the diazonium cation, are very reactive species that attack all kinds of material surfaces (conductor, semiconductor or insulator) and attach onto them. Therefore, the modification of the surfaces with aryldiazonium salts is a versatile method in contrast to many other molecules used for surface modification reactions, such as thiols [7,8], silanes, phosphonic acids, [9] and etc. Moreover, the synthetic and isolation routes for the aryldiazonium cations are simple [3]; the de-diazonation methods are easy to achieve, allowing the possibility to modify semiconducting [10] and conducting material surfaces [3,4]. A strong feature that makes this method appealing for surface modification reactions is also the remarkable stability of the nanocomposite structure generated after the attachment of aryl moieties on the electrode surface. Experimental [2,4,11] and theoretical studies [12-16] support the formation of the covalent bond between material surfaces and aryl groups [4]. There are a vast number of examples that involve the usage of the grafted layers in a number of applications ranging from corrosion protection [17,18] to photovoltaics [3]. In this study, the covalently grafted 2D pyridinic layers onto the Pt and GC (Glassy Carbon) surface, issued from their corresponding diazonium salts, were explored for the complexation of the copper (II) ions. Moreover, this is the first study to our knowledge that not only uses the theoretical calculation to evaluate the binding energy of the grafted pyridinic layer, but also the interaction (adsorption energy) of the copper (II) ions with this grafted layer. This is of utmost importance as the application for such interfaces can have benefits for sensor construction, corrosion protection, catalysis, pre-concentration of heavy metals etc. 


\section{Experimental part}

\subsection{Instrumentation}

A PalmSens ${ }^{3}$ potentiostat was used along with a threeelectrode cell at $298 \mathrm{~K}$. A graphite rod $(\mathrm{d}=5 \mathrm{~mm}, 1=6$ $\mathrm{cm})$ served as an auxiliary electrode and the saturated calomel electrode (SCE) as a reference electrode. The working electrode was a $3 \mathrm{~mm}$ GC or $0.5 \mathrm{~mm}$ Pt embedded into Teflon holder (tube). The SW measurement was performed using a pulse amplitude of $100 \mathrm{mV}$, and a 100 $\mathrm{Hz}$ frequency.

\section{2 "In-situ" synthesis of 6-chloropyridine- diazonium chloride}

Prior to the grafting reaction, diazopyridinum salt was synthesized "in situ" in aqueous acid solution of 6-chloropyridin-3-amine ( $2 \mathrm{mM})$ and $\mathrm{HCl}(0.1 \mathrm{M})$ in which an equimolar amount of sodium nitrite (dissolved in minimum amount of water) was added. The solution was left to react for $5 \mathrm{~min}$ and was degassed by bubbling high purity nitrogen, prior to the electrochemical grafting

\subsection{Grafting reaction and the preconcentra- tion of copper (II) ions}

The grafting reaction is performed using Cyclic Voltammetry by imposing 20 potential cycles from +0.15 to $-0.65 \mathrm{~V} / \mathrm{SCE}$, with a scan rate of $100 \mathrm{mV} / \mathrm{s}$. To assess the film formation by observing the blocking effect of the film for an electron transfer we have used a $2 \mathrm{mM}$ $\mathrm{K}_{3}\left[\mathrm{Fe}(\mathrm{CN})_{6}\right]$ aqueous solution as a redox probe. The preconcentration (complexation) of the copper (II) ions is achieved by dipping the modified electrode with organic layer in the $0.1 \mathrm{mM}$ solution of copper (II) ions (dissolved in phosphate buffer $\mathrm{pH} \approx 7$ ). The electrochemical response of the electrode after immersion in the solution with copper (II) ions is performed using SW.

\section{Computational details}

We have performed the calculation of the Bond Dissociation Energy (BDE) [13,15] of the grafted pyridine moiety onto the 9 atom Pt cluster [19] and the effect of the second bonded moiety. Furthermore, the adsorption of copper (II) ions (in monodentate and bidentate mode) was also investigated. In both cases, the DFT method employing the Generalized Gradient Approximation (GGA) [20]/PBE (Perdew-Burke-Ernzerhof ) form [15,,] was used. The calculations were based on the double-numeric quality with polarization functions (DNP) basis set [].

The interaction energy, both, in vacuum is evaluated as follow [22,23]:

$$
\begin{aligned}
& \mathrm{E}_{\mathrm{BDE}}=\mathrm{E}_{\mathrm{Pt9} \text {-pyridine }}-\left(\mathrm{E}_{\text {pyridine radical }}{ }+\mathrm{E}_{\mathrm{Ptg}}\right) \\
& \text { (for one bonded pyridine moiety) } \\
& \mathrm{E}_{\mathrm{BDE}}=\mathrm{E}_{\mathrm{Ptg}-2 \text { pyridine }}-\left(2^{\star} \mathrm{E}_{\text {pyridine radical* }}+\mathrm{E}_{\mathrm{Pt}}\right) \\
& \text { (for two bonded pyridine moiety) } \\
& \mathrm{E}_{\text {interaction }}=\mathrm{E}_{\mathrm{P} \text { t9-pyridine/copper (II) }}-\left(\mathrm{E}_{\mathrm{Pt} \text {-pyridine }}+\mathrm{E}_{\text {copper (II) }}\right) \\
& \text { (for monodentate complexation mode) } \\
& \mathrm{E}_{\text {interaction }}=\mathrm{E}_{\mathrm{Pt9} \text {-2pyridine/copper (II) }}-\left(\mathrm{E}_{\mathrm{Ptg} \text {-2pyridine }}+\mathrm{E}_{\text {copper (II) }}\right) \\
& \text { (for bidentate complexation mode) }
\end{aligned}
$$

Ethical approval: The conducted research is not related to either human or animal use.

\section{Results and Discussion}

The grafting reaction scheme is presented in Scheme 1. As mentioned above, the first step is the synthesis of the corresponding aryldiazonium cation followed by subsequent grafting. The voltammograms obtained during the grafting reactions of GC and Pt electrodes are presented in Figure 1. The shape and current of the voltammogram follows the typical grafting features as observed with other aryldiazonium cations [2,3,10].

The observed current decrease is due to the blocking effect of the formed organic film during the electrochemical reduction of diazonium, which prevents the electron transfer from the electrode surface and the reduction of other diazonium species thus limiting further film growth [1,2,4].

The current drifts observed in the case of Pt electrode are due to the hydrogen evolution reaction (as the grafting is performed in acidic medium). The reduction potential is at $\mathrm{E} \sim-0.25 \mathrm{~V}$ in the case of the glassy carbon electrode. A rough estimation of the surface modification percentage can be obtained simply by evaluating the current decrease in each grafting cycle. The steady behavior of the current in both cases is observed only after performing $20 \mathrm{CV}$, thus these conditions are taken as a maximum possible mean to completely modify both of electrodes. The presence of 
a)<smiles>Cc1ccc(Cl)nc1</smiles>

b)

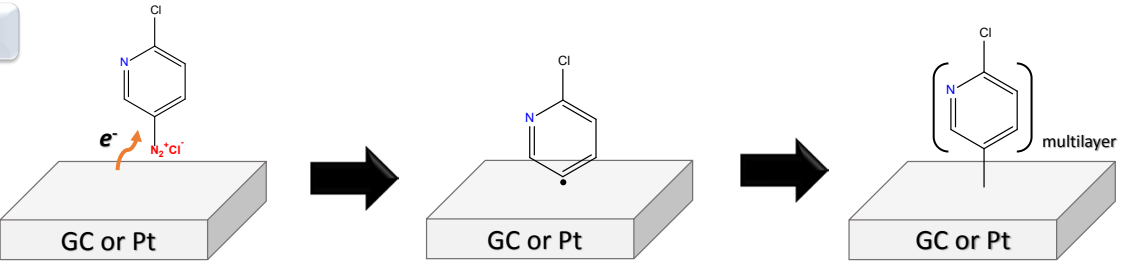

c)

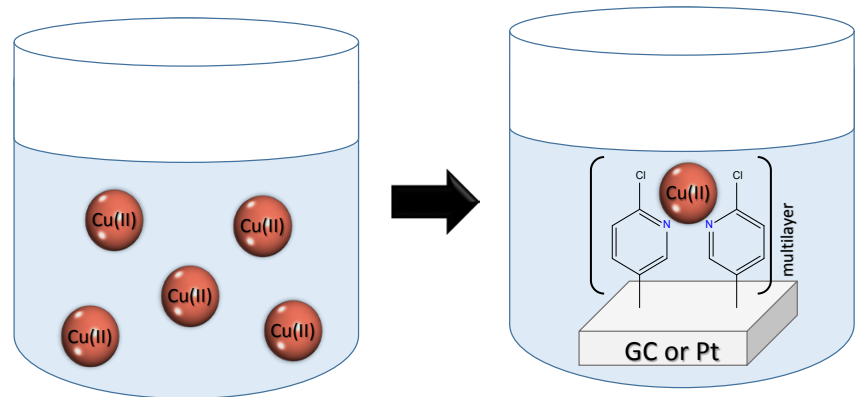

Scheme 1: a) "In-situ" transformation of the 6-chloropyridin-3-amine in to its corresponding diazonium salt. b) Electrochemical grafting of the diazonium salt that was formed "in-situ" c) Complexation of copper (II) ions onto the grafted GC or Pt surface.
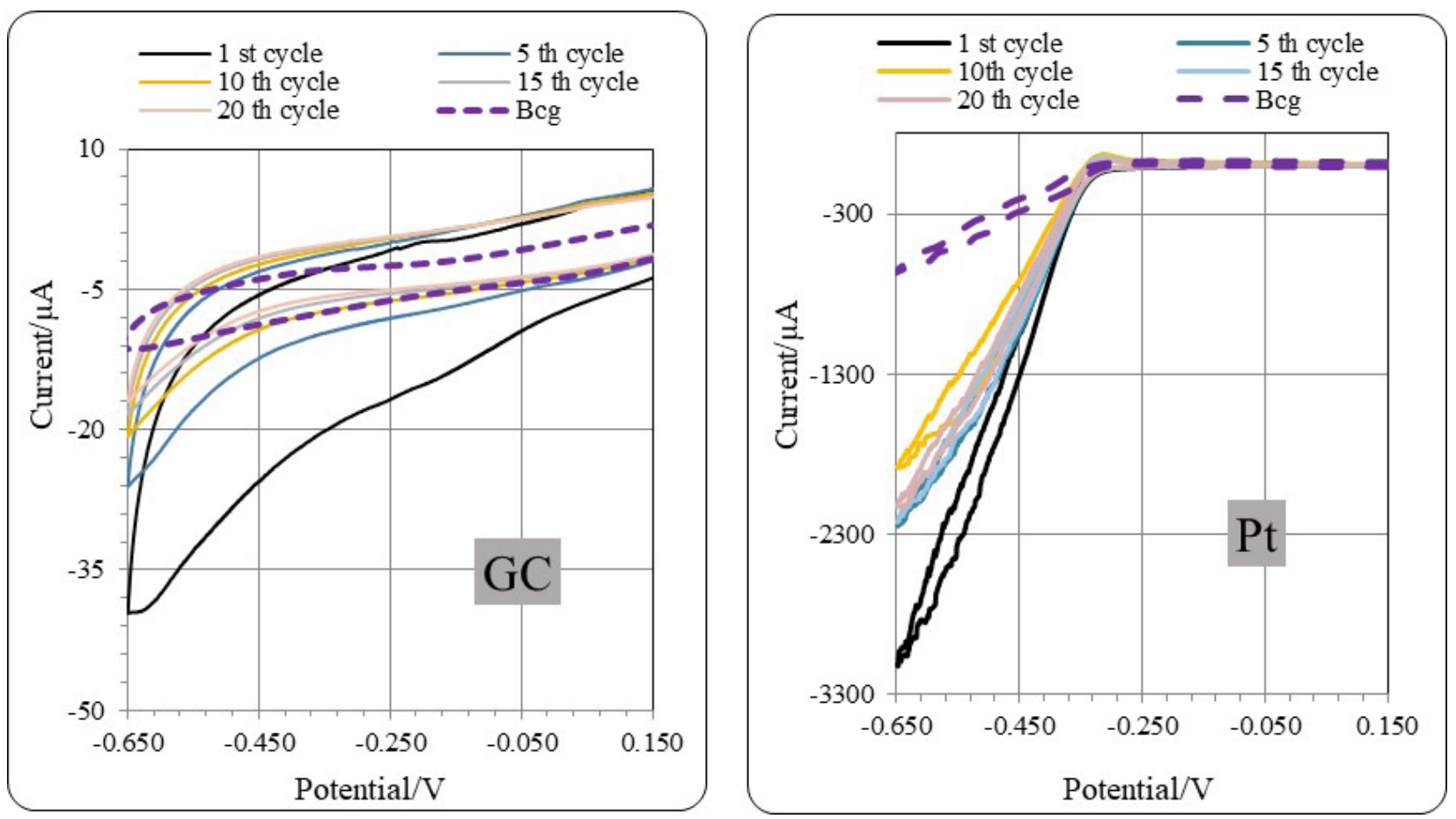

Figure 1: Cyclic voltammograms for Pt and GC electrodes in pyridine diazonium solution prepared “'in situ”: (a) $1^{\text {st }}$, b) $5^{\text {th }}$, c) $10^{\text {th }}$, d) $15^{\text {th }}$, e) $20^{\text {th }}$ and f) Bcg scans. Scan rate $0.1 \mathrm{~V} \mathrm{~s}^{-1}$. 

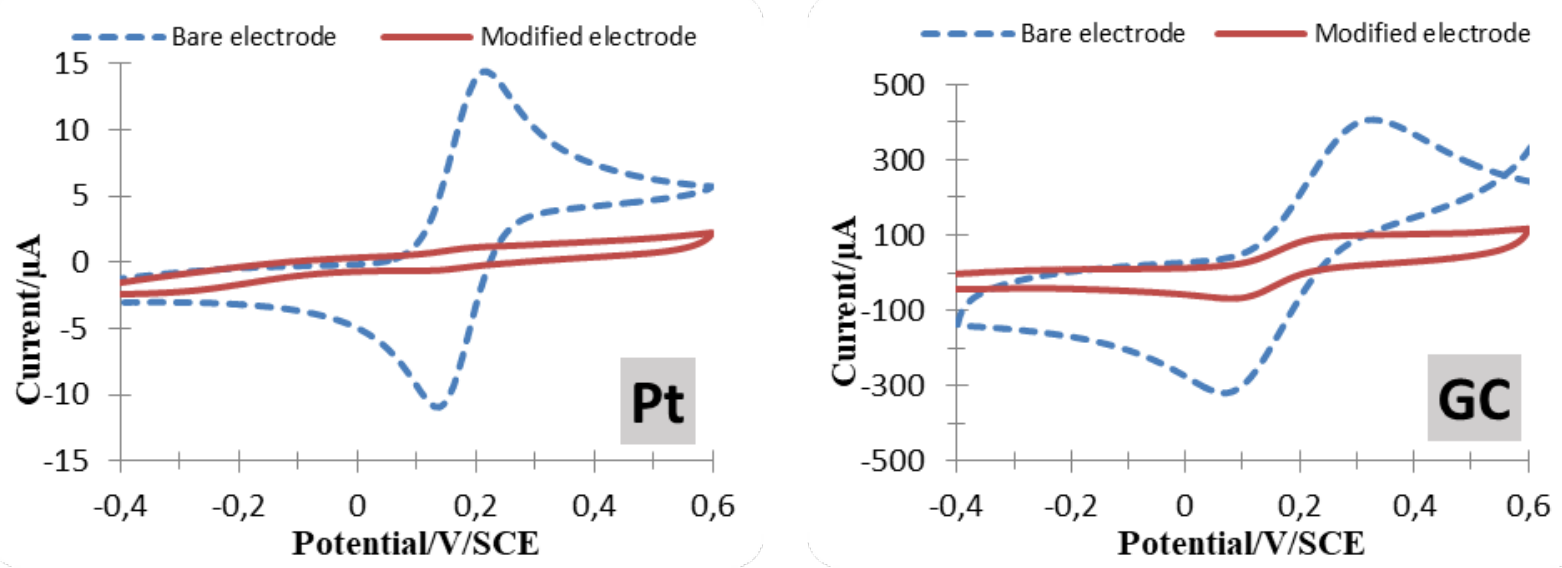

Figure 2: Cyclic voltammograms for the: bare and modified electrode surfaces in the presence of $0.1 \mathrm{M} \mathrm{KCl}+2 \mathrm{mM} \mathrm{K}_{3}\left[\mathrm{Fe}(\mathrm{CN})_{6}\right]$ aqueous solution, $\mathrm{pH}$ 7, phosphate buffer.

the grafted layer onto the electrode surface is evaluated by using a redox probe such as the $\left[\mathrm{Fe}(\mathrm{CN})_{6}\right]^{3-} /\left[\mathrm{Fe}(\mathrm{CN})_{6}\right]^{4-}$ couple. In Figure 2 shows the cyclic voltammograms of bare and modified electrodes for both platinum and glassy carbon electrodes. The current decrease and peak potential separations between the bare and the grafted electrode surfaces are evident as observed in previously reported studies on grafting reactions using diazonium salts [1,4].

From the voltammograms, it is clearly seen that the decrease of the current in the case of the modified electrode, as expected, is due to the electron blocking behavior of the grafted organic layer.

In order to achieve the surface complexation of copper (II) ions, the rinsed modified electrode surfaces were dipped in $0.1 \mathrm{mM}$ of copper (II) ions in ammonium acetate buffer solution (at $\mathrm{pH} \approx 7$ ). After the complexation of copper (II) ions with grafted pyridinium moieties on platinum and glassy carbon surfaces (preconcentration of copper (II) ions), the electrodes were rinsed and immersed in an electrochemical cell containing only the electrolyte solution. The assessment of the complexation of copper (II) ions by modified glassy carbon electrode is done by SW potential scan (Figure 3). It can be observed, in the case of bare GC electrode immersed in the acetate buffer solution containing $0.4 \mathrm{mM}$ copper (II) ions, two current peaks at $\mathrm{E}_{1}=-0.08 \mathrm{~V}\left(\mathrm{I}_{1}=-40 \mu \mathrm{A}\right)$ and $\mathrm{E}_{2}=-0.70 \mathrm{~V}\left(\mathrm{I}_{2}=-14.5\right.$ $\mu \mathrm{A})$ that represents different equilibrium copper (II) ions $(+\mathrm{I}$ and $+\mathrm{II})$ (Figure 3d). For electrolyte solution in the bare electrode (Figure 3a), there are no electrochemical signals as expected, the same remains true when the measurement was performed in the solution of 6-chloropyridin-3-amine or grafted with 6-chloropyridine

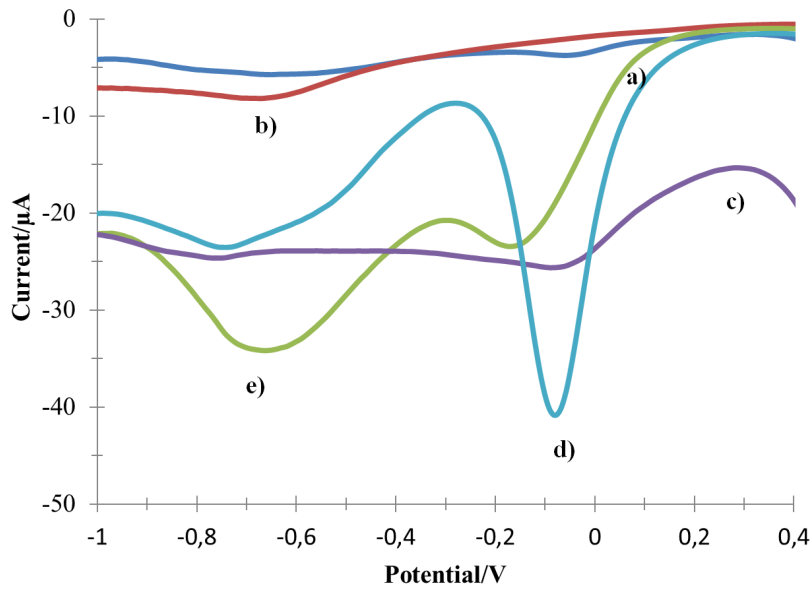

Figure 3: The SW voltammograms of GC electrode in acetate buffer solution: a) bare electrode; b) immersed in 6-chloropyridin-3-amine; c) modified with 6-chloropyridine moieties, d) bare electrode + $4.0 \times 10^{-4} \mathrm{M}$ copper (II) ions and e) modified with 6-chloropyridine moieties after complexation with copper (II) ion for $45 \mathrm{~min}$. The SW amplitude, $100 \mathrm{mV}$, SW frequency, $100 \mathrm{~Hz}$.

moieties (Figure 3b and 3c). The GC electrode grafted with 6-chloropyridine moieties was immersed during $45 \mathrm{~min}$ in the aqueous solution with copper (II) ions and thereafter the electrochemical signal of complexed ions is obtained at lower potential (- $0.17 \mathrm{~V} / \mathrm{SCE}$ ) than free copper (II) ions.

The ability of pyridine grafted film to link copper (II) ions is studied at molecular level by DFT calculations which first is employed to evaluate the binding energy of the layer. This parameter is important as it shows the stability of the formed layers [15,16,23]. The optimized geometry for all species in the grafting reaction is shown in Figure 4. 


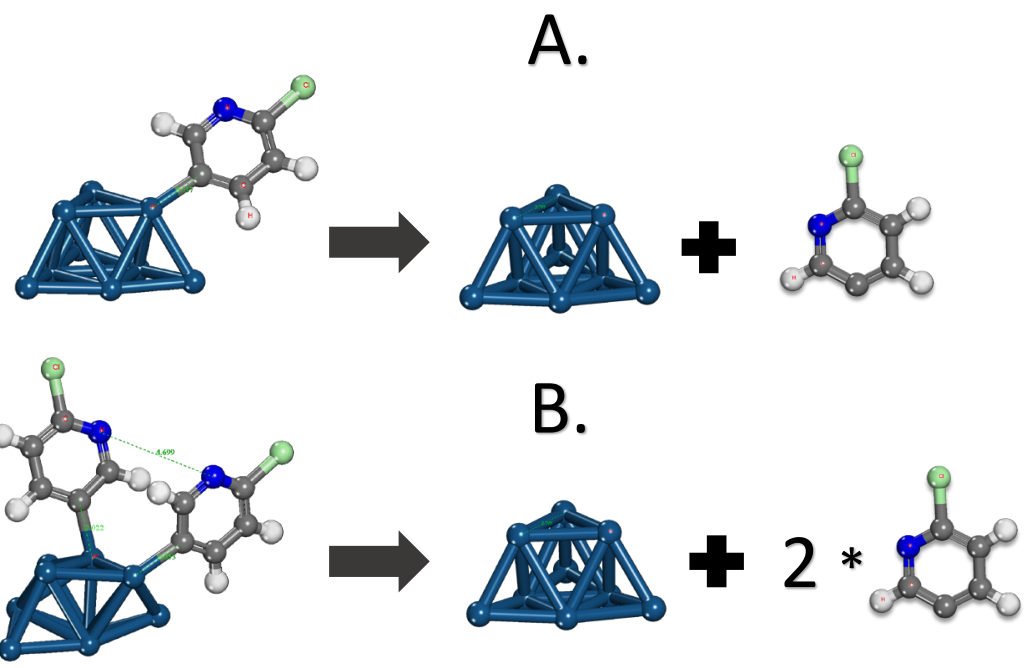

Figure 4: Bond dissociation energies (calculated by DFT based on GGA/PBE and double-numeric quality with polarization function) for a platinum claster of 9 atoms grafted with: A. one and B. two grafted pyridine moieties.
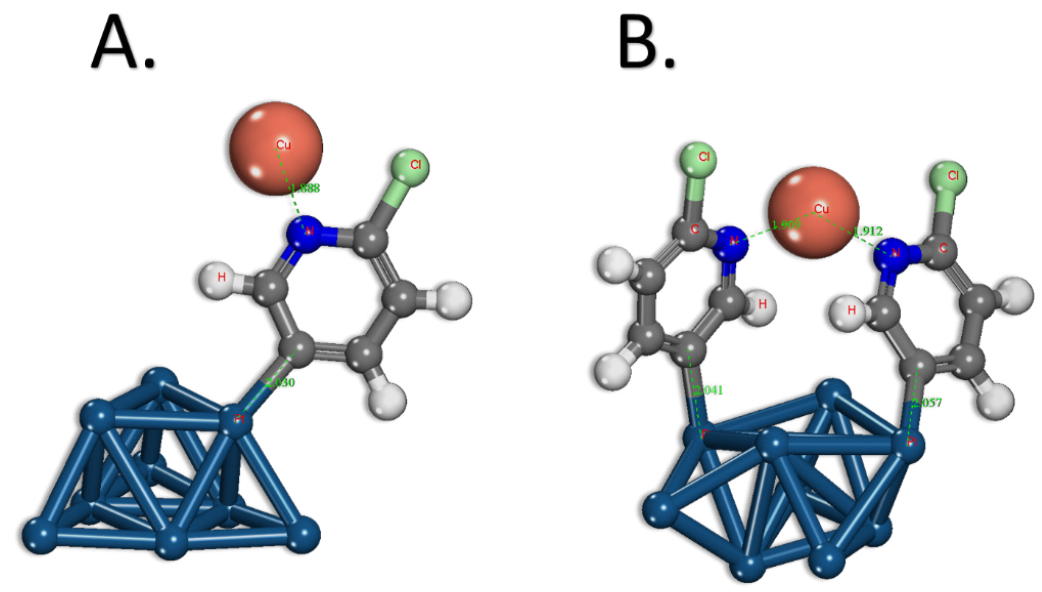

Figure 5: The optimized structures for the interaction of copper (II) ions with: A. one (mono-dentate) and B. two (bi-dentate) two attached chloropyridine groups.

The bond dissociation in the case of one grafted chloropyridine moiety is $-70.14 \mathrm{kcal} / \mathrm{mol}$, whereas in the case of two such grafted moieties is $-140.58 \mathrm{kcal} / \mathrm{mol}$. This high stabilization effect of the second grafted group is observed when two phenyl groups are bonded to the para positions of the same six-membered ring to form a pair on the basal plane [19]. These significant high values obtained from BDE support the high stability of the formed interface, which is of primary interest in the materials science. Figure 5 presents the geometries of the copper (II) ions adsorption onto the pyridine grafted layer for mono- and bi-dentate interaction modes. These results gave insights regarding the complexation ability of these layers (to our knowledge this represents the first study). The Pt-C bond length is $2.037 \AA$ which is shorter than that of Au-C bond [11]. The copper (II) ions when interacting with a single grafted moiety are at the distance of $1.88 \AA$ from the $\mathrm{N}$ atom of the pyridine ring. In the case of the bi-dentate mode of interaction (Figure 5, B) this distance of copper (II) ions, sandwiched between $\mathrm{N}$ atoms of the 
two rings is $1.91 \AA$. These relatively close distances lead to high complexation energies, -201.8 for a mono- and -248.8 $\mathrm{kcal} / \mathrm{mol}$ for bi-dentate complexation mode.

\section{Conclusions}

This paper describes the grafting of pyridine moieties derived from corresponding 'in- situ" prepared 6-chloropyridine-diazonium chloride salt onto platinum and GC surface. The SW measurements have proven that the grafted pyridine layer has served to complex the copper (II) ions and therefore this organic film may be used for their detection. DFT calculations support a strong binding of the pyridine moieties onto the $\mathrm{Pt}$ surface. The most favorable complexation mode of copper (II) ions as suggested from DFT is the bidentate mode. The experimental data and theoretical calculations derived from this study shows the importance of the grafting of aromatic and heteroaromatic cycles for the modification of the material surfaces and the possible application of the nanocomposite.

Conflict of interest: Authors declare no conflict of interest.

\section{References}

[1] Delamar M., Hitmi R., Pinson J., Saveant, J. M., Covalent Modification of Carbon Surfaces by Grafting of Functionalized Aryl Radicals Produced from Electrochemical Reduction of Diazonium Salts, J. Am. Chem. Soc., 1992, 114, 5883-5884.

[2] Pinson J., Podvorica F., Attachment of organic layers to conductive or semiconductive surfaces by reduction of diazonium salts, Chem. Soc. Rev., 2005, 34, 429-439.

[3] Belanger D., Pinson J., Electrografting: A Powerful Method for Surface Modification, Chem. Soc. Rev., 2011, 40, 3995-4048.

[4] Berisha A., Chehimi M., Pinson J., Podvorica F., Electrode Surface Modification Using Diazonium Salts, Electroanalytical Chemistry, A Series of Advances: Vol. 26, Edited by Bard A.J., Zoski C.G., Taylor\&Francis group, 2015.

[5] McCreery R.L., Yan H., Bergren A.J., A critical perspective on molecular electronic junctions: there is plenty of room in the middle, Phys. Chem. Chem. Phys., 2013, 15, 1065-1081.

[6] Cao C., Zhang Y., Jiang C., Qi, M., Liu G., Advances on Aryldiazonium Salt Chemistry Based Interfacial Fabrication for Sensing Applications, ACS Appl. Mater. Interfaces 2017, 9, 5031-5049.

[7] Love J.C., Estroff L.A., Kriebel J.K., Nuzzo R.G., Whitesides G,M., Self-Assembled Monolayers of Thiolates on Metals as a form of Nanotechnology, Chem, Rev., 2005, 105, 1103-1170.

[8] Pensa E., Cortès E., Cortey G., Carro P., Vericat C., Fonticelli M. $\mathrm{H}$., et al., The chemistry of the sulfur-gold interface: in search of a unified model, Acc. Chem. Res., 2012, 45, 1183-1192.
[9] Pujari S.P., Scheres L., Marcelis A.T.M., Zuilhof H., Covalent Surface Modification of Oxide Surfaces, Angew. Chemie Int. Ed.,. 2014, 53, 6322-6356.

[10] Mahouche-Chergui S., Gam-Derouich S., Mangeney C., Chehimi, M.M., Aryl diazonium salts: a new class of coupling agents for bonding polymers, biomacromolecules and nanoparticles to surfaces, Chem. Soc. Rev., 2011, 40, 41434166.

[11] Halili J., Salihu F., Berisha A., Covalent Attachment of Phenyl and Carboxyphenyl Layers Derived from Diazonium Salts onto Activated Charcoal for the Adsorption of Pesticides, Maced. J. Chem. Chem. Eng., 2018, 37, 71-78.

[12] Jiang D.-e., Sumpter B. G., Dai S., Structure and Bonding between an Aryl Group and Metal Surfaces, J. Am. Chem. Soc., 2006, 128, 6030-6031.

[13] Jiang D.-e., Sumpter B., Dai S., How Do Aryl Groups Attach to a Graphene Sheet? J. Phys. Chem. B, 2006, 110, 23628-23632.

[14] Tang Q., Jiang D.-e., Computational Insight into the Covalent Organic-Inorganic Interface, Chem. Mater., 2016, 28, 59765988.

[15] Berisha A., Combellas C., Kanoufi F., Médard J., Decorse P., Mangeney C., et al., Alkyl-Modified Gold Surfaces: Characterization of the Au-C Bond, Langmuir, 2018, 34, 11264-11271.

[16] Berisha A., Combellas C., Kanoufi F., Decorse P., Oturan N., Médard J., et al., Theoretical and Experimental Insights on the Mechanistic Routes Leading to the Spontaneous Grafting of Gold Surfaces by Diazonium Salts, Langmuir 2017, 33, 87308738.

[17] Podvorica F.I., Combellas C., Delamar M., Kanoufi F., Pinson J., Passivation of Metals and Semiconductors and Properties of Thin Oxide Layers, 1st Edition, Edited by Marcus P., Maurice V., Elsevier, 2006.

[18] Berisha A., Combellas C., Kanoufi F., Pinson J., Podvorica F.I., Physisorption vs Grafting of Aryldiazonium Salts onto Iron: A Corrosion Study, Electrochim. Acta, 2011, 56, 10762-10766.

[19] Nie A., Wu J., Zhou C., Yao S., Luo C., Forrey R.C., et al., Structural evolution of subnano platinum clusters, Int. J. Quantum Chem., 2007, 107, 219-224.

[20] Perdew J.P., Burke K., Ernzerhof M., Generalized Gradient Approximation Made Simple, Phys. Rev. Lett., 1996, 77, 3865-3868.

[21] Seydou M., Lassoued K., Tielens F., Maurel F., Raouafi F., Diawara B., A DFT-D Study of Hydrogen Adsorption on Functionalized Graphene, RSC Adv. 2015, 5, 14400-14406.

[22] Gautier S., Steinmann S.N., Michel C., Fleurat-Lessard P., Sautet P., Molecular adsorption at Pt(111). How accurate are DFT functionals?, Phys. Chem. Chem. Phys., 2015, 17, 2892128930.

[23] Berisha A., Interactions between the Aryldiazonium Cations and Graphene Oxide: A DFT Study, Journal of Chemistry, 2019, Article ID 5126071. https://doi.org/10.1155/2019/5126071. 